\title{
The Effects of a Mastery Learning Strategy on Knowledge Acquisition Among Aboriginal Students: An Experimental Approach
}

\author{
Mohd Hasril Amiruddin ${ }^{1}$, Fathin Liyana Zainudin ${ }^{2}$ \\ ${ }^{1}$ Faculty of Technical and Vocational Education, Universiti Tun Hussein Onn Malaysia, Johor, Malaysia \\ ${ }^{2}$ Faculty of Electrical and Electronics Engineering, Universiti Tun Hussein Onn Malaysia, Johor, Malaysia
}

Email address:

hasril@uthm.com (M. H. Amiruddin), fathin.liyana.zainudin@gmail.com (F. L. Zainudin)

\section{To cite this article:}

Mohd Hasril Amiruddin, Fathin Liyana Zainudin. The Effects of a Mastery Learning Strategy on Knowledge Acquisition Among Aboriginal Students: An Experimental Approach. International Journal of Vocational Education and Training Research. Vol. 1, No. 2, 2015, pp. $22-26$. doi: 10.11648/j.ijvetr.20150102.12

\begin{abstract}
Research indicates that low academic achievement amongst Aboriginal (Orang Asli) students is due to the current practices of teaching and learning in the classrooms. Additionally, the diversity of students for this community leads to different cognitive abilities and cultures, which contributing to major issues of teaching and learning effectiveness. As a part of special education community, there is a need for a review of teaching and learning strategies for Aboriginal students in the context of an entrepreneurship education. This paper addresses low academic achievement amongst Aboriginal students using mastery learning strategy (MLS) and investigates its effectiveness in the entrepreneurship education course. An experimental, pre-test and post-test, with control group design was implemented on 80 Aboriginal students from two department of Orang Asli Development Training Center in Malaysia. Students in the experimental groups were treated using MLS throughout 12 weeks. Students' knowledge acquisition (achievement) was tested using multiple choices question, and the results were compared to the traditional learning approach (TLA) group. The findings indicated that the MLS was more effective than TLA in enhancing students' knowledge acquisition. The implication is that the model used in this study is appropriate for teaching, promoting learning, and conducting research among Orang Asli students.
\end{abstract}

Keywords: Mastery Learning, Entrepreneurship Education, Academic Achievement, Aboriginal Students

\section{Introduction}

Research indicates that low academic achievement is one of the major reasons, contributing to low socio-economic levels for the minority such as Aboriginal people [1]. Statistic indicates that the drop-out rate for Aboriginal students in primary school is 54.8 percent, while 45.8 percent of Aboriginal people are not going to school [2]. Only six out of 1,000 Aboriginal children who have managed to complete until form five of schooling, leading to a small number of access into higher educational institutions (HEIs) $[3,4,5]$. The most recent report from JHEOA, in 2009, only 368 Aboriginal students have managed to get place in public HEIs. As a result, only 652 graduates from 1971 to 2007 has been produced [1].

In this context, Aboriginal people should be more aware of the importance of education, as the only way to compete within Malaysian society [5,6]. Nevertheless, some
Aboriginal people have been skeptical regarding the potential of education as a way out of poverty [6].

According to $[2,6]$, academic achievement among Aboriginal people has lagged far behind achievement among Malaysian students in general [1]. As a result, very limited numbers (only 60 students in 2008) of Aboriginal youth aged between 19 to 35 years have managed to further study in HEI [1].

One major reason for low academic achievement amongst Aboriginal students is due to effectiveness of teaching and learning strategies in the classrooms [6,7]. Also, the diversity of Aboriginal students in terms of cognitive abilities and cultures contributes to this gap. Therefore, the strategies for learning and teaching Aboriginal students must be changed. It is proposed that the strategies to be enhanced and enriched using various methods of delivery in similar contexts with similar content. Previous research suggests that learning methods depends on the materials used as well as the students' circumstances [8]. Educators need to provide more 
proactive and responsive teaching strategies in order to improve education for Aboriginal peoples [9,10].

In this capacity, several authors suggest that MLS does have potential to be an effective method for teaching minority groups such as aboriginal students $[11,12]$. However, there has been limited literature and empirical data to support this contention. For this reason, this study was conducted to investigate the effect of a mastery learning strategy (MLS) on students' achievement in entrepreneurship classes. Then, the study also compares the effectiveness of MLS and the traditional learning approach (TLA) as methods of improving students' achievement.

\section{Mastery Learning Strategies (MLS)}

The concept of mastery learning was initiated by the work of John B. Carroll [8] and Benjamin Bloom in the 1960s $[9,10]$ Bloom indicates that it is an effective way to improve student attitudes and interest toward learning, besides helping them to master in specific knowledge [11,12].

The basic theoretical assumption of mastery learning is that students must have predetermined set of necessary skills and knowledge in order to achieve their learning objectives [8]. In other words, they need to acquire a foundation of appropriate knowledge to master the next concepts $[9,10]$. They are likely to fail if they do not acquire this pre-requisite knowledge, because they do not have the appropriate cognitive skills and sets of information [12].

In keeping with this assumption, a mastery learning strategy requires students to reach a particular level of mastery (usually 80 to 100 percent) of a topic before proceed to the next topics [8]. The implementation of MLS is according to a set of process shown in Figure 1 [10].

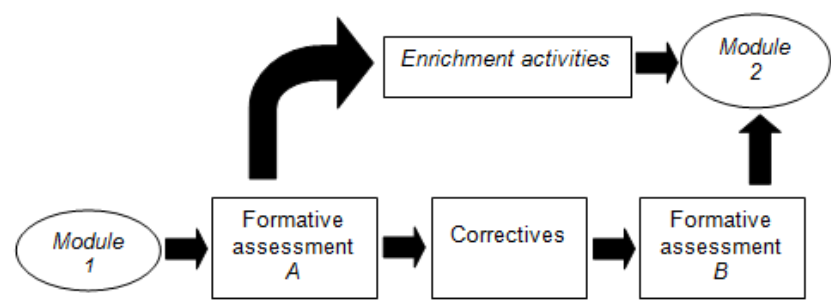

Figure 1. The process of mastery learning strategies.

In MLS, teaching materials and concepts must be organized into small units appropriately [8]. After teaching a small unit, teachers will give students a quiz or test as a means of formative assessment, intended to probe students' learning achievement on the topic. Next, students are given further lesson according to particular identified area, using intensive exercises. This exercises are focusing on particular concepts, before a different formative assessment are using to test students' improvement. Several advantages of MLS have been highlighted by previous researchers $[8,9,10]$ are listed as follows:

- Ensuring better students' achievement of total understanding (up to $80 \%$ ) of current learning materials before introducing the next challenging topics.
- The requirement that teachers perform a task analysis that will ready them for teaching particular material to their students.

- The prior identification (before instruction) of teaching/learning objectives.

- Reduction of the dropout rate, especially for minority and at-risk students.

Although mastery learning has generally been agreed to be an appropriate approach for Aboriginal students [8], one critical aspect must be considered, that is, student motivation during the learning process. Research indicates that motivation can be increased through mastery learning $[9,10,11,12]$, within an encouraging environment and appropriate teaching aids.

Previous studies on the effects of learning strategies in entrepreneurship education have employed models and learning approaches such as Kolb's Model [13] problem-based learning [14], interactive learning [15], mentoring [16], experiential learning [13] active learning [14] and project-based learning [15], and in disciplines such as mathematics[17,19] and physics [9]. However, few or no such studies have considered entrepreneurship education. Therefore, in this study, MLS is used within a module-based entrepreneurship education course.

\section{Method}

An experimental, pre-test and post-test with a control group design was conducted in two JAKOA Training Centres using a new module for basic entrepreneurial education. Two methods of instruction were used; the experimental group $(n=40)$ was exposed to basic entrepreneurial knowledge using MLS, while the control group $(n=40)$ was using TLA, which mainly based on lectures and assignments.

Several variables were controlled such as using similar content and materials, equivalent level of samples in both groups, and number of days and events for instructions. The teachers of the two classes had almost equivalent in term of experience and same level of qualifications. In addition, a double-blind method was used whereby the teachers and students involved in this study were not informed of the experiment being conducted [20]. The independent variable was the method of instruction (MLS vs. TLA), while the dependent variable was the students' academic achievement.

Sampling: The study involved 80 Orang Asli students consisting of 34 male and 46 female. The subjects were randomly selected amongst students from the Department of Orang Asli Development Training Centres, locatein Paya Bungor Kuantan, Pahang and in Damansara Damai in Selangor. The 34 male students (experimental group $=17$, control group $=17$ ) who attended the GIATMARA Damansara Damai were enrolled in the vehicle repair skills course, while the 46 female students (experimental group $=23$, control group $=23$ ) from Orang Asli Development Training Centre Paya Bungor were enrolled in the manufacture of women's clothing. Gender distribution across groups was equal. Respondents were generally have similar backgrounds and 
had no experience inbusiness. Respondents had at least Penilaian Menengah Rendah level on their academic record (a requirement to enroll at the Training Centre).

Entrepreneurial Education Module (EEM): The EEM was designed and developed to build on previous secondary school and polytechnic entrepreneurship modules. The basic content was then carefully selected to achieve the requirement of basic knowledge of entrepreneurship. Finally, the EEM was validated by several experts in entrepreneurship education.

Treatment Procedures: The EEM was used as an instruction material throughout the 12 weeks of the treatment. At the end of the study, both groups were given a post-test.

Experimental group (MLS): In the experimental group, the treatment was according to special model and module designed. However in general, right after the first instruction ends, the teacher administered a brief formative assessment based on the unit's learning goals. The assessment provided students with feedback to identify what they had learned to that point (diagnostic feedback) and what they needed to learn better (prescriptive feedback). In this case, students who had successfully acquired the concepts continued their learning experience with enrichment activities such as case studies, problem-solving tasks, and exercises. While students who needed more experience, in contrast, will be given a paired feedback paired and corrective activities that are offering guidance and direction to remedy. To be effective, these corrective activities were qualitatively different from the initial instruction, offering effective instructional approaches and additional time to learn. Furthermore, learning goals and standards must be aligned with instruction (or opportunities to practice), corrective feedback, and evaluation.

Finally, students were given feedback about their individual learning progress at regular intervals throughout the instructional period. This feedback was intended to help them identify what they had and had not learned well. Areas that were not learned well were allotted more time, so that students could achieve mastery.

Control group (TLA): In brief, the procedures in the control group followed a traditional learning approach (TLA); the lecturer was typically active in delivering information and facts, and explaining terms, concepts, and procedures.

Instrumentation: Pre-test and post-tests were used to measure students' knowledge acquisition. The tests consisted of 35 multiple-choice questions, 30 right/wrong questions, three matching questions, two fill-in-the-blank questions, five structured questions, and one essay question. Items were designed based on the six cognitive levels of Bloom's taxonomy. The total number of marks was 100, and item validity was confirmed by lecturers in entrepreneurship education.

Data analysis: Inferential statistical tools were used including ANOVA and t-test, using SPSS software. ANOVA can be used in cases where there are two or more groups to find significant differences among sample means. Meanwhile, the t-test assesses whether the means of two groups are statistically different from each other. This approach is simple and appropriate as post-test in a two-group experimental design.

\section{Results}

ANOVA was performed to test the pre-experiment condition of students' knowledge of basic entrepreneurship (homogeneity of variance between groups). The result, as shown in Table 1, shows no significant difference between groups $(\mathrm{F}(1,78)=.353, \mathrm{p}<.05)$.

Table 1. ANOVA for the basic entrepreneurship test score (pre-test).

\begin{tabular}{llllll}
\hline Source & Type III Sum of Squares & df & Mean Square & F & Sig. \\
\hline Group & 31.250 & 1 & 31.250 & .353 & .55 \\
Error & 6907.950 & 78 & 88.563 & & \\
\hline
\end{tabular}

a. R Squared $=.005$ (Adjusted R Squared $=-.008$ )

Meanwhile, Table2 shows normality test results based on the pre-test score, using Kolmogorov-Smirnov and Shapiro-Wilk tests.

Table 2. Kolmogorov-Smirnov test and Shapiro-Wilk test.

\begin{tabular}{lllllll}
\hline & \multicolumn{3}{l}{ Kolmogorov-Smirnova } & \multicolumn{4}{l}{ Shapiro-Wilk } \\
\hline Group & Statistic & df & Sig. & Statistic & df & Sig. \\
Experimental & .066 & 40 & $.200^{*}$ & .990 & 40 & .970 \\
Control & .097 & 40 & $.200^{*}$ & .981 & 40 & .727 \\
\hline
\end{tabular}

Kolmogorov-Smirnov results show significance in both groups $($ Sig. $=.200)$, as do Shapiro-Wilktests(Sig. $=.970$ in the experimental group and .727 in the control group). In all cases, significance is more than .05. Thus, the significance values were not in violation of the assumption of normality. Therefore, control and experimental groups are assumed to have had equivalent levels of knowledge of entrepreneurship at the beginning of the study, permitting further analysis using the t-test to measure gain from treatment. The results are indicated in Tables 3 and Tables 4.

Table 3. Mean score of the pre-tests and post-tests on Entrepreneurship.

\begin{tabular}{lll}
\hline Grouping & Mean score & SD \\
\hline Experimental Group & & \\
Pre-test score & 41.97 & 9.84 \\
Post-test score & 68.47 & 7.21 \\
Control Group & & \\
Pre-test score & 43.22 & 8.95 \\
Post-test score & 55.90 & 10.86 \\
\hline
\end{tabular}

Table 3 indicates that the mean post-test score on knowledge of entrepreneurship in the experimental group exceeds the mean score of the control group the scores are $68.47(\mathrm{SD}=7.21)$ and $55.90(10.86)$, respectively. As shown in Table 4, knowledge acquisition of basic entrepreneurship is significant base on ANCOVA result $[\mathrm{F}(1,77)=45.00$, $\mathrm{p}>.05]$, indicating a significant difference between groups on knowledge of basic entrepreneurship. However, the results showed that there was no main effect of control variables PRE-TEST SCORE significantly to the dependent 
variable $[(1,77)=11: 54, p<.05]$. These results show significantly that by controlling PRE-TEST SCORE respondents, the value in GROUP intervention is influencing the increase basic entrepreneurial achievement among respondents.

Table 4. T-test for the basic entrepreneurship test.

\begin{tabular}{llllll}
\hline Source & $\begin{array}{l}\text { Type III Sum } \\
\text { of Squares }\end{array}$ & df & Mean Square & F & Sig. \\
\hline Correcte & $4027.553^{\mathrm{a}}$ & 2 & 2013.77 & 26.861 & .000 \\
$\begin{array}{l}\text { Model } \\
\text { Intercept }\end{array}$ & 8065.531 & 1 & 8065.53 & 107.584 & .000 \\
Pretest & 8640.941 & 1 & 8640.94 & 11.537 & .101 \\
Score & 3373.746 & 1 & 3373.74 & 45.002 & .000 \\
Group & 5772.634 & 77 & 74.969 & & \\
Error & 319183.000 & 80 & & & \\
Total & & & & \\
Corrected & 9800.188 & 79 & & & \\
Total &
\end{tabular}

a. $\mathrm{R}$ Squared $=.411$ (Adjusted R Squared $=.396)$

While by comparing the effect size based standard deviation (experimental $=7.21$; control $=10.86$ ) and mean difference (experimental $=68.47$; control $=55.9$ ) for the two treatment groups showed the effect sizes are at the stage .56 . By classification Cohen, this indicates that the learning strategy used for experimental groups provide great impact on the achievement of basic entrepreneurship. In this study the effect size showed significant differences in the impact of intervention in experimental group (by using MLS) and control groups (by using TLA).

\section{Analysis and Discussions}

As the results show, using MLS significantly increased acquisition of entrepreneurship knowledge as compared to TLA among aboriginal participants. The effect size (.68) was medium, with a power of 0.32 .

The implementation of mastery learning strategies in the learning of basic entrepreneurship was one of the options presented above to help in solving problems faced by aboriginal students. The findings support the theory of Mastery Learning and the findings of previous research $[8,21]$. This study has also proven that the teaching and learning strategies employed influence the level of cognitive change in students, as described in $[22,23]$.

These results are also in line with those of several previous studies [9,10,11,12,17,19,21], where MLS improved students' understanding of basic concepts in entrepreneurship education. In addition, several authors $[13,14,15,16]$ agree that the use of a diversity of learning strategies in entrepreneurship education provide an encouraging environment and interesting, interactive, and effective learning climate for minority students.

In this study, several aspects of MLS might have been contributed to the promotion of knowledge acquisition amongst the students. Repeated focus-group treatments for low-scoring students were seen as the key success factor. This is supported by the mastery learning model, where in a follow-up test after the first unit, the group was successful but could not reach the mastery criterion; this was achieved only after corrective training. In the second unit, however, the learning criterion was achieved without any corrective training. This is interpreted as a sign that the students eventually adapted to the mastery learning process. These results clearly show that the MLS has significantly affected the achievement of Aboriginal students positively in entrepreneurship education as compared to TLA.

MLS stresses cooperative skills more than mastery of content. As used in this study, this emphasis was partly corrected through corrective feedback and remediation. Previous research comparing the effects of MLS and of regular teaching methods on student achievement [10], the result showed that MLS alone (without feedback) had significantly increased achievement [11]; the present study shows that students who received feedback as part of MLS had higher achievement scores in both immediate achievement and long-term retention.

However, MLS involves the provision of extra time to carry out activities such as formative assessment, enrichment activities, and corrective activities. The findings of this study are in line with these results. Apart from feedback, time is another aspects of MLS needs to be highly considered. Mastery learning theorists, especially [22,23], contend that MLS reduces the amount of time needed to achieve mastery. A study conducted by [23] on achievement, time, and learning rate found that use of MLS significantly increases achievement levels but the time needed is considerable.

To reduce time impediments with the implementation of MLS in this study, teachers were carefully trained to use the MLS teaching method. Learning materials were prepared to ensure that after teaching, testing was done, followed by remedial instruction and retesting. Continued interaction with the process helped the teachers to discover students' areas of weakness and therefore assisted the students to reach the expected level of competence. MLS also helped the students achieve deeper understanding of the concepts of entrepreneurship.

\section{Conclusion}

This paper proposed MLS as a part of effectively learning strategies in entrepreneurship education especially for aboriginal students in Malaysian. An experimental, pre-test and post-test with control group was used to test the effectiveness on students' knowledge acquisition in entrepreneurship. The result, a significant difference was indicated by the achievements of the experimental groups, compared to the control group. For future research, more studies are needed using similar samples and models, researchers are suggested to replicate the approach with bigger samples and aboriginal students of different proficiency levels, as well as to explore the extent to which each learning strategy contributes to learning success. More significant findings are expected to contribute to the existing limited. 


\section{References}

[1] Z. A. Ali, "Peranan Jabatan Hal Ehwal Orang Asli (JHEOA) dalam pembangunan masyarakat Orang Asli, In. Marof Redzuan \& Sarjit S. Gill. 2008," Orang Asli: Isu, Transformasi dan Cabaran. Serdang: Universiti Putra Malaysia, pp. 1-24, 2008.

[2] R. Mustapha, M. Omar, R. M. Yassin, and N. M. Salleh, "Aspirasi kerjaya dan minat vokasional dalam kalangan belia Orang Asli," In the Proceedings of the Persidangan Serantau Pendidikan Inklusif dan Pendidikan Kanak-Kanak Berkeperluan Khas, pp. 280-295, 2009.

[3] N. Othman and M. H. Amiruddin, "Different perspective of learning styles from VARK model," Procedia Social and Behavioral Sciences, vol. 7, pp. 652-660, 2010.

[4] N. Othman, M. H. Amiruddin and H. Hussein, "Entrepreneurial behaviour and non-cognitive entrepreneurship knowledge among the Orang Asli youths from the south zone of peninsular Malaysia," In the Proceedings of the 10th WSEAS International Conference on Education and Educational Technology (EDU '11), pp. 207-211, 2011.

[5] N. Othman and M. H. Amiruddin, "The readiness of the Orang Asli youths in venturing into entrepreneurship," In the proceedings of the 9th WSEAS International Conference on Education And Educational Technology (EDU '10), pp. 235-240, 2010.

[6] N. Othman, M. H. Amiruddin, and M. Mansor, "The entrepreneurial behavior of Orang Asli youths in south peninsular Malaysia," International Journal of Education and Information Technologies, vol. 1 no. 5, pp. 132-139, 2011.

[7] R. J. Murphy, S. A. Gray, S. R. Straja, and M. C. Bogert, "Student learning preferences and teaching implications. Educational Methodologies," Journal of Dental Education, vol. 68 no.8, pp. 859-866, 2004

[8] T. R. Guskey, "Closing achievement gaps: revisiting Benjamin S. Bloom's learning for mastery," Journal of Advanced Academics, vol. 19 no. 1, pp. 8-31, 2007.

[9] Kristen, C. Schellhase., "Applying mastery learning to athletic training education," Athletic Training Education Journal, vol. 3 no. 4, pp. 130-134, 2008.

[10] B. J. Zimmerman and M. K. Dibenedetto, "Mastery learning and assessment: Implications for students and teachers in an era of high-stakes testing," Psychology in the Schools, vol. 45 no. 3 , pp. 206-216, 2008.

[11] M. Ozden, "Improving science and technology education achievement using mastery learning model," World Applied Sciences Journal, vol. 5 no. 1, pp. 62-67, 2008.

[12] I. Y. Kazu, H. Kazu, and O. Ozdemir, "The effects of mastery learning model on the success of the students who attended: usage of basic information technologie scourse," Educational Technology \& Society, vol. 8 no. 4, pp. 233-243. 2005.

[13] N. E. Peterman, and J. Kennedy, "Enterprise education: Perception of entrepreneurship," Entrepreneurship Theory and Practice, vol. 28 no. 2, pp. 129-144, 2003

[14] A. Collins and M. Robertson, "The entrepreneurial summer school as a successful model for teaching enterprise," Education \& Training, vol. 45 no. 6, pp. 324-330, 2003.

[15] K. Lewis, "The best of intention: future plans of young enterprise scheme participants," Education \& Training, vol. 47 no. 1, pp. 470-483, 2005.

[16] V. Vij and S. Ball, "Exploring the impact of entrepreneurship education on university non-business under- graduates," International Journal of Entrepreneurship and Small Business, vol. 9 no. 1 , pp. $86-109,2010$.

[17] P. W. Wambugu and J. M. Changeiywo, "Effects of mastery learning approach on secondary school students' physics achievement," Eurasia Journal of Mathematics, Science \& Technology Education, vol. 4 no. 3, pp. 293-302, 2008.

[18] E. Davrajoo, R. A. Tarmizi, M. Nawawi, and A. Hassan," Enhancing algebraic conceptual knowledge with aid of module using mastery learning approach," Procedia - Social and Behavioral Sciences International Conference on Mathematics Education Research (ICMER 2010), vol. 8, pp: 362-369, 2010.

[19] D. H. McBurney and T. L. White, "Research Methods," Belmont, USA: Wadsworth Cengage Learning, 2009.

[20] P. W. Wambugu and J. M., Changeiywo, "Effects of mastery learning approach on secondary school students' physics achievement," Eurasia Journal of Mathematics, Science \& Technology Education, vol. 4 no. 3, pp. 293-302, 2008.

[21] E. W. Eisner, "Benjamin Bloom 1913-99," UNESCO International Bureau of Education, vol. 3, pp. 1-7, 2000.

[22] B. S. Bloom, "The 2 Sigma Problem: The Search for Methods of Group Instruction as Effective as One-on-One Tutoring," Educational Researcher, vol. 13 no. 6, pp. 4-16. 1984. 